\title{
LOS ALMIDONES RESISTENTES Y LA SALUD
}

\section{Carmen Carla Quiroga Ledezma}

\section{RESUMEN}

El cambio en los hábitos alimenticios es uno de los factores responsables para el incremento en los niveles de obesidad, diabetes, enfermedades cardiovasculares e intestinales. Estas tendencias globales han despertado preocupación e interés en la comunidad científica y público en general que han centrado su atención en los macronutrientes (carbohidratos, proteínas y grasas), particularmente en el uso de fibra dietética: fibra dietética soluble, almidón resistente, y carbohidratos de digestión lenta. Investigaciones realizadas sobre almidones resistentes muestran una relación entre la velocidad de degradación de los carbohidratos durante la digestión y la regulación de los niveles postprandiales de azúcar en la sangre e insulina, y el funcionamiento saludable del sistema gastrointestinal.

Para una mejor comprensión de los almidones resistentes y su efecto en la salud se hizo una revisión bibliográfica de los trabajos publicados: estructura del almidón, tipos de modificaciones a la estructura del almidón, digestión del almidón, tipos de almidones, consecuencias fisiológicas del almidón resistente y tendencias futuras.

Palabras Clave: Almidón Resistente, Almidón Lentamente Digerible, Fibra Dietética, Índice Glucémico/Índice Glicémico, Cáncer Colorectal/Cáncer de Colon. 